\title{
Milk Feeding, Solid Feeding, and Obesity Risk: A Review of the Relationships Between Early Life Feeding Practices and Later Adiposity
}

\author{
Claire Farrow • Emma Haycraft • Gemma Mitchell
}

Published online: 9 October 2012

(C) Springer Science+Business Media New York 2012

\begin{abstract}
Childhood obesity is a major health issue with associated ill-health consequences during childhood and into later adolescence and adulthood. Given that eating behaviors are formed during early childhood, it is important to evaluate the relationships between early life feeding practices and later child adiposity. This review describes and evaluates recent literature exploring associations between child weight and the mode of milk feeding, the age of introducing solid foods and caregivers' solid feeding practices. There are many inconsistencies in the literature linking early life feeding to later obesity risk and discrepancies may be related to inconsistent definitions, or a lack of control for confounding variables. This review summarizes the literature in this area and identifies the need for large scale longitudinal studies to effectively explore how early life feeding experiences may interact with each other and with nutritional provision during later childhood to predict obesity risk.
\end{abstract}

Keywords Infancy $\cdot$ Breastfeeding $\cdot$ Formula feeding · Restriction · Overweight · Weaning · Introduction to solid foods $\cdot$ Obesity $\cdot$ Adiposity

\section{Introduction}

Obesity during childhood is a major health issue of paramount importance. According to recent US statistics from 2009-10, $12.1 \%$ of children aged $2-5$ years were obese [1]. Childhood obesity has many adverse health consequences during childhood that are associated with increased risks for

C. Farrow $(\bowtie) \cdot$ E. Haycraft $\cdot$ G. Mitchell

School of Sport, Exercise \& Health Sciences, Loughborough

University Centre for Research into Eating Disorders,

Loughborough University,

Leicestershire LE11 3TU, UK

e-mail: c.v.farrow@1boro.ac.uk morbidity and early mortality in adulthood [2, 3]. Given this, there is a pressing need to understand the role of early life factors that exacerbate the risk of childhood obesity and one area of importance is that of early life feeding. There are two main types of feeding that healthy children will experience during infancy; the first is milk feeding and the second is the feeding of solid foods. This review will focus on recent research that has evaluated the impact of breastfeeding compared to formula feeding, the duration of breastfeeding, the age of the child's introduction to solids and the way that solid foods are fed to the child, in terms of their impact on subsequent child weight gain and eating.

\section{Milk Feeding: Breast or Bottle Feeding}

Studies investigating the association between breastfeeding initiation, duration, and obesity risk in infancy have often been undermined by the presence of confounding variables that dilute the association, such as socioeconomic status, smoking exposure and differences in the method of data analysis [4]. As a result, the real strength of the relationship between breastfeeding and obesity risk, and the nature of the mechanism underlying it, remains unclear. Despite this, a review in 2004 [5] concluded that breastfeeding does offer a small and consistent protective effect. To date, research is continuing to focus on understanding how and why the initiation and duration of breastfeeding may protect against obesity. The most recent research relating to what and how an infant is fed, and the effects upon weight gain, will be outlined here.

\section{Macronutrients and Compounds - Differences \\ Between Formula and Breast Milk}

The relationship between breastfeeding versus formula feeding and the risk of obesity has been suggested to be mediated 
by the difference in the protein content associated with each method of feeding. Formula milk tends to be higher in protein than breast milk and may render the child at a greater risk of weight gain during infancy. Although protein is a very satiating macronutrient, intakes in excess of metabolic requirements may enhance the secretion of insulin and insulin-like growth factors (IGF-I) that can lead to accelerated growth and increased adipose tissue. Indeed, positive associations have been found between protein intake and IGF-I and child weight and IGF-I [6]. Recently this hypothesis has been tested by Koletzko et al. [7] who reported the results of a randomized trial of over 1,000 infants across Europe comparing high and low protein formula milks. The results suggested that lower protein milk normalizes growth to that of a breastfeeding reference group and that compositional changes in formula milk can be exploited to help reduce the elevated risk of obesity associated with formula feeding. Indeed, a new formula milk has recently emerged on supermarket shelves that has increased whey protein, as found in breast milk, and decreased beta protein, not typically found in breast milk. Research has shown that babies fed the new formula have an early rate of weight gain closer to that of a breastfed baby than to a baby fed other infant formula milk [8].

The exact nature of the relationship between protein intake and weight gain has recently been investigated by the European Childhood Obesity Trial Group [9]. Forty-one infants were randomized at birth to receive either high or low protein content formula, along with 25 breastfed infants. The infants receiving the high protein formula had significantly higher weight, weight-for-length, and BMI compared to the low protein and breastfed groups at 6 months of age. At 12 months of age, BMI and weight-for-length were still significantly greater in the high compared to low protein groups, but by 24 months, all differences were no longer significant. Importantly, these researchers looked at fat mass and fat-free mass measurements and found that BMI and weight-forlength $\mathrm{z}$ scores correlated significantly with fat mass, but not fat-free mass. Breastfed babies had significantly lower fat mass, but not fat-free mass, than both groups of formula fed babies. It is concluded that protein increases fat mass specifically, which may lead to increased BMI in future years, and that greater fat-free mass may offer protection against overweight and obesity since muscle mass predicts glucose uptake and the capacity for physical exertion [10].

Other compounds that are absent from formula milk, but which are found in breast milk, may also be important. For example, growth factors in human breast milk are associated with infant size and body composition. Specifically, insulin is negatively associated with size, growth and lean mass; TNF- $\alpha$ is associated with lower lean mass; and IL-6 concentration is negatively associated with infant growth and adiposity [11]. Leptin, which occurs naturally in breast milk and is believed to play a role in hunger regulation and satiety, is also absent from formula milk and may therefore contribute to increased intake [12].

\section{Breastfeeding Duration and Protective Effects}

The length for which a child is exclusively breastfed has been suggested to be important. Generally, it is believed that the longer the duration of breastfeeding, the lower the risk of obesity. Indeed, McCrory and Layte [13] reported a doseresponsive effect in those infants breastfed for more than 4 weeks, such that a feeding duration of 13-25 weeks was associated with a $38 \%$ reduction in risk of obesity at age 9 , and a duration of more than 26 weeks was associated with a reduction in risk of $51 \%$. Scott et al. [14] examined breastfeeding duration on weight status in 2066 Australian 916 year olds and found that being breastfed for 6 months or more was associated with a decreased likelihood of being overweight or obese in later childhood. Importantly, this study controlled for many confounding variables including maternal characteristics, mean energy intake, level of physical activity, screen time, and sleep duration. However, other research has found that a significant relationship between the duration of exclusive breastfeeding and an increased risk of child overweight at age 10 disappears when confounding variables are controlled for [15]. Similarly, other authors acknowledge that factors such as sampling variability may nullify the reported associations at a population level [16].

\section{The Feeding Context: Differences Between Breast Versus Bottle Feeding}

Behaviorally, the differences in the method of feeding between breast and bottle, as opposed to the content of the feed, cannot be ignored, and the experience of bottle versus breast feeding appears to be significantly different for both the infant and the caregiver. Li et al. [17••] recently reported that, irrespective of milk type (breast versus formula), infant weight gain was related to the mode of delivery, such that bottle-feeding was associated with more weight gain. A further study of 1,250 infants found that $27 \%$ of infants fed exclusively at the breast in early infancy emptied the bottle or cup in late infancy. However, $54 \%$ of infants who were fed both at the breast and by bottle and $68 \%$ of those who were fed only by bottle emptied the bottle or cup in late infancy, again irrespective of milk type in the bottle [18]. This suggests that bottle feeding may undermine an infant's ability to self-regulate their intake which may be a risk factor for later overweight and obesity [19]. One reason for this may be that infants fed from the bottle are less able to control the flow of milk and therefore may consume more than required. Furthermore, caregivers may encourage infants to consume all that is in a bottle, irrespective of the child's hunger. This may be particularly true in cases where 
an infant is perceived to be of low weight and/or not eating 'enough' and parental anxiety is high [20]. Bottle feeding allows parents to see how much milk a child has consumed and therefore push greater intake if they feel that this is not 'enough'. In contrast, the amount of milk that a breastfed child has consumed cannot be assessed in this way. Anxious parents may also modify the milk powder-to-water ratio in order to increase the relative calorie content of a feed, something which cannot be manipulated with relatively homogenous breast milk. Indeed, mistakes in the preparation of bottle feeds are believed to be common [21]. These finding are important since increasing numbers of women are relying on bottle feeding (either breast or formula milk) as the method to feed their child.

It is clear that while the differences in the compounds present in differing milks can influence weight gain, the social and socioeconomic context in which feeding takes place is likely to be equally important. Overall, the relationship between breastfeeding initiation, duration, and obesity risk is difficult to unpick, due to the many confounding parental, environmental, and statistical factors that are present in such studies. One such factor strongly associated with the mode of feeding during infancy is the timing of the introduction to solid foods.

\section{The Age of Introducing Solid Foods}

In 2001, based on a systematic review [22], the World Health Organization recommended that children are exclusively breastfed until 6 months of age and that solid foods are offered from this time onward. The change in this guideline, which previously recommended introducing solid foods from around 4 months of age in many countries, has been met with resistance from many caregivers. Many studies have been conducted to attempt to explore whether, in environments where sanitation is good and the risk of gastrointestinal infection from solid feeding is low, there are medical risks associated with introducing solids prior to 6 months. This research is complicated by the fact that few women exclusively breastfeed to 6 months; indeed the median age of introducing solid foods in Europe appears to be around 19 weeks [23]. Much controversy surrounds the medical benefits and risks associated with early compared to later introduction to solids foods, and it is beyond the scope of this review to evaluate this literature here (for a review see [22]). In a recent systematic review, Moorcroft et al. [24] conclude that there is no clear association between the timing of the introduction to solid foods and later obesity risk, and that often positive associations are reported in studies which do not adequately control for confounds. However the data are further complicated by different definitions of what is considered to be 'early' introduction to solid foods.

\section{Introducing Solids Before 15 Weeks and Obesity Risk}

In terms of the relationship between the age of introduction to solid foods and any risk of childhood obesity, research suggests that very early introduction to solid foods (before 15 weeks) may have a detrimental impact on child adiposity. For example, Wilson et al. [25] reported that the introduction to solid foods before infants were 15 weeks old was related to increased body fat and weight at age 7 compared to those introduced to solid foods after 15 weeks. In a prospective cohort study, Grote et al. [23] found that European infants introduced to solids at or before 13 weeks (and those introduced between 18 and 21 weeks) grew faster and were heavier at 6 months than infants introduced between 13 and 18 weeks of age or after 22 weeks. However the timing of the introduction to solid foods was not significantly associated with child anthropometrics at 24 months, suggesting that any impact on child growth appears to be transitory. Other results from Indian populations have suggested that children introduced to solid foods later (comparing $\leq 3,4,5, \geq 6$ month olds) tended to have a slightly lower risk of a high BMI at age 5, however the differences between the groups were negligible after adjusting for confounding factors [16]. Various mechanisms have been proposed to account for how very early introduction to solid foods may impact on child weight gain (if any relationship can be consistently identified), for example: through the intake of excess protein during infancy which may increase insulin like growth factor -1 levels and promote earlier adiposity rebound; or through altering the secretion of hormones such as ghrelin; or levels of gut flora resulting in epigenetic modifications of metabolic programming [15].

The relationships between earlier introduction to solid foods and subsequent child weight and BMI are complicated by the influence of various confounding variables which are often adjusted for in research studies. However, given the associations reported between breastfeeding and obesity described above, it is often difficult to disentangle the relationships between breastfeeding and the age of introduction to solid foods, given that families who formula-feed are more likely to offer solid foods earlier [26]. In a recent study of 847 children from a prospective pre-birth cohort study conducted by Huh et al. [27], associations between the age of introduction to solid foods ( $<4,4-5$, and $\geq 6$ months) with later child obesity at age 3 were compared among children who were breastfed for 4 months or more and those who were never breastfed or fed for less than 4 months. After adjusting for various confounding characteristics, Huh et al. report that in children who were breastfed the timing of the introduction to solid foods was not associated with later obesity. Whereas, children who were formula-fed and introduced to solid foods before 4 months of age were 6 times more likely to be obese at age 3 . Overall these results 
suggest that very early introduction to solid foods may have a detrimental impact on the child's risk for overweight, but that this risk may be limited to children who are never breastfed or not breastfed for long. This may be a consequence of the fact that formula-fed children carry a higher risk of over-feeding and overweight, as described above, and the authors suggest that whilst breastfed infants may be more apt at self-regulation and displace milk for solid foods, formula fed infants may be more likely to increase their overall energy intake when solids are introduced.

\section{Introducing Solids at 4 or 6 Months and Subsequent Obesity Risk}

In terms of comparing children who are introduced to solids at 4 versus 6 months of age, there appears to be no evidence of any ill-effect on subsequent weight. Indeed, Burdette et al. [28] report that the introduction to solids before compared to after 4 months of age had no effect on child adiposity at age 5 using dual energy x-ray absorptiometry, whilst Reilly et al. [29] found that the timing of complementary feeding was not related to BMI at age 7. Recently, Seach et al. [15] did find that after controlling for various confounding variables, the age of introduction to solid foods predicted the child's risk of overweight at age 10. In their sample, the median age of introduction to solid foods was 20 weeks with the prevalence of childhood overweight being $34.7 \%$ in those children starting solid foods before 20 weeks and the risk decreasing to $19.4 \%$ in those starting solid foods after 24 weeks. However, this study did not control for maternal or paternal BMI which are known to predict child weight status.

Another important consideration is that children who are given solid foods earlier are simply hungrier babies who are likely to be bigger anyway. Scott et al. [26] report that $55 \%$ of mothers who introduce solids prior to 17 weeks say that they do so because their baby is hungry or big for their age, and data from Fewtrell et al. [30] have indicated that child weight at 6 weeks of age was a strong predictor of the age of weaning. Data from the UK Millennium cohort study [31] suggest that age of introduction to solids was not associated with faster weight gain after adjusting for height $\mathrm{z}$ scores at age 3, indicating that stature mediates any effect of age of introduction to solid food upon weight gain. Recent research by Rossem et al. [32••] supports this by comparing three groups of children who were introduced to solid foods before 3 months, between 3-6 months, and after 6 months. After adjusting for various confounding variables they found that the children introduced to solid foods between 3 and 6 months of age were those who had gained the most weight prior to the introduction of solids. After the introduction of solids, children introduced before 6 months showed a relative decrease in their weight-for-length and there were no differences in weight-for-length changes between the three groups of children after 12 months of age. Overall these results suggest that differences in child weight-for-height are not the result of early introduction to solid foods but rather that solids may be introduced earlier in response to infant weight.

Future research should consider not simply the age of introduction to solid foods but also what nutrition is given during the period of 4/6 -24 months in populations with greater prevalence of child overweight to allow for meaningful comparisons [16]. In summary various authors have suggested that guidelines should be used flexibly and it may not be that one size fits all in terms of determining when solid foods are offered to infants [33]. Solid foods should not be introduced before 4 months of age, but the evidence for harm in terms of child adiposity or weight from introducing solids at 4 months compared to at 6 months appears to be weak.

\section{Solid Feeding Practices}

Once children have been weaned onto solid foods, parents/ caregivers are still integral to the child's feeding environment. They are responsible for what their children eat and failure to provide a healthy diet or offering children inappropriately large portions are associated with greater child weight $[34,35]$. Furthermore, a great body of research evidence has now emerged which explores whether the types of feeding practices that caregivers use when feeding solid foods are predictive of subsequent child weight and eating behavior. Overly controlling feeding practices, such as pressuring an infant or child to eat more than $\mathrm{s} / \mathrm{he}$ wishes or restricting the intake of foods, are believed to undermine the ability to self-regulate energy intake and thereby predict problems with eating and weight gain in children. While researchers generally agree that a permissive or indulgent parental feeding style, typified by a lack of control, is not helpful for children in today's obesogenic society [35], most research in this field suggests that feeding practices which are overly controlling are detrimental to child health. Increased parental control of child eating behavior has been shown to be counterproductive to parents' presumed intentions concerning food [34]. For example, parental use of pressure to eat has been shown to be related to children's decreased liking of pressured foods [36] and to predict lower child adiposity over time [37], while the use of restriction of food, or forbidding food, has been related to children eating in the absence of hunger [37] and predicts greater child weight and weight gain over time [38, 39]. These relationships may in part be exacerbated by the fact that parents tend to pressure children to eat foods such as vegetables which are associated with child health, but restrict sugary and highfat foods which are often perceived as more palatable and more likely to lead to weight gain. 


\section{Controlling Feeding Practices: Cause or Consequence of Child Weight?}

Authors have rightly questioned whether these overly controlling feeding practices do indeed predict changes in child weight, or whether parents use these feeding practices in response to existing concerns about child eating and weight. Gross et al. [40 $]$ examined maternal feeding practices and infant weight status in a sample of 208 infants aged 2 weeks to 6 months. They found evidence that restriction of food was linked to maternal concern about their infant becoming overweight, and the use of pressure to eat was related to concern about their child becoming underweight. This study provides evidence that feeding practices may reflect parents' concerns about their child's future healthy development. Other research suggests that restriction of food intake may be implemented with children who are already overweight, perhaps in response to child weight status. Rifas-Shiman et al. [41] found that, after adjusting for parent and child sociodemographic characteristics, maternal use of restriction at age 1 was associated with higher child BMI $z$ scores at age 3 before, but not after, adjusting for child weight-forlength scores at age 1. Similarly, Brown and Lee [42] found that parents used greater restriction of unhealthy foods with 612 month old infants who had a higher BMI. Taveras et al. [43] have demonstrated similar associations between restriction and increased obesity risk in their sample of over 2,000 ethnically diverse families of children aged up to 4 years.

Thus, there is a strong body of evidence which suggests that parents may restrict (unhealthy) food intake when their children are overweight or when they perceive them to be at risk of overweight. It is therefore questionable whether restrictive feeding practices are directly predictive of higher child weight status given the confounds presented by parental concerns and perceptions about earlier child weight. In a longitudinal study, Farrow and Blissett have attempted to tease apart these relationships and found that, while greater restriction of food during infancy predicts lower child weight at age 2 (perhaps because children at this age are still usually solely dependent on caregivers for the amount of food they can consume; [37]), by 5 years of age the use of earlier maternal restriction predicts greater child weight scores [44]. These findings suggest that the detrimental effects of overly restricting children's access to foods may not always be apparent during early infancy and this may reinforce parental use of restriction which appears to be predictive of problems with regulating food intake and overeating during early childhood.

\section{Other, Non-Controlling Feeding Practices and Children's Weight}

In addition to the impact of parents overly controlling food intake, there are a variety of other child feeding practices which have been less well explored which are also likely to be implicated in the development of over-eating and the risk of obesity. One such practice is emotional feeding or using food to soothe negative emotions. Stifter et al. [45] examined maternal use of food to soothe distress in their sample of 3 to 34-month-old children. After controlling for significant covariates, they found that infant weight was positively related to maternal use of food to soothe, and suggested that this feeding practice may teach children to eat in response to external cues rather than internal hunger signals and predispose them to weight gain. Similarly, these children may also learn to associate eating with emotional comfort; a behavior which has been linked to obesity in adults [46]. The type of food used to soothe is also a potentially important contributor to child overweight as parents report a tendency to offer sweet, sugary foods to more emotional children [47]. In our own research with preschool children (aged 3-4 years) we have also found that children whose mothers report using food to regulate their child's emotions eat more sweet foods in the absence of hunger than children whose parents do not use this feeding practice [48], suggesting that this feeding practice may impact upon child eating and weight across early childhood.

Instead of using controlling or indulgent feeding practices, parents can employ a range of other feeding behaviors which have more positive associations with children's eating and weight. These include modeling healthy eating, eating with their child, and making healthy foods available [49-51]. Palfreyman et al. [51] found mothers who reported more modeling of eating behaviors, and who ate more healthy foods themselves (e.g., more fruit and vegetables) had children (aged 1.5 to 8 years) who ate more fruit, vegetables and salads. Other research has found that offering children a variety of foods from a young age is linked to healthier child eating practices and that more responsive feeding, where parents decide what the child eats but the child decides how much to consume, is recommended for helping children to develop healthy eating behaviors [49].

\section{Conclusions}

In summary, this review has explored the role of breastfeeding, the age of introduction to solid foods, and the ways that solid foods are presented to children in relation to the risk of obesity during infancy and early childhood. The findings from recent literature in this field suggest that the relationships between early life feeding practices and later child obesity risk are complex and often confounded by various demographic and lifestyle factors which render children at greater risk of weight gain, such as maternal smoking, parental BMI and socio-economic status. Overall the findings suggest that breastfeeding may have a small protective 
effect against subsequent obesity, although this association is often negligible when confounding factors are appropriately controlled for. Similarly it appears that the very early introduction to solid foods (before 13 weeks) may be associated with faster early weight gain, but that this effect may only be transitory, may possibly be greater in infants who are never breastfed, and potentially not significant when controlling for other confounding variables, such as breastfeeding or socio-economic status. Finally, the ways that foods are fed to children can have a substantial impact on subsequent child food choices and their ability to regulate food intake in later life, and a large body of research has now demonstrated that overly restricting high calorie foods may actually be associated with child weight gain over time.

Despite the wealth of literature in this field, there is a dearth of large scale longitudinal studies with adequate power to explore obesity risk which appropriately control for confounding variables. Clearly these different variables do not exist in a vacuum and future research is required to integrate the effects of the range of feeding practices across infancy. That is, to determine how the mode of milk feeding interacts with the age of introducing solids, and how these factors may determine subsequent styles of solid feeding which may additionally impact upon child feeding and weight. Only by exploring how these variables interact to protect from or exacerbate obesity risk will we be able to confidently inform the feeding practices of caregivers to optimize child weight status and healthy development.

Disclosure No potential conflicts of interest relevant to this article were reported.

\section{References}

Papers of particular interest, published recently, have been highlighted as:

- Of importance

•. Of major importance

1. Ogden CL, Carroll MD, Kit BK, Flegal KM. Prevalence of Obesity in the United States, 2009-2010, NCHS. Data Brief 82, U.S. Department of Health and Human Services Centers for Disease Control and Prevention, 2012. National Center for Health Statistics.

2. Strand BH, Kuh D, Shah I, Guralnik J, Hardy R. Childhood, adolescent and early adult body mass index in relation to adult mortality: results from the British 1946 birth cohort. J Epidemiol Community Health. 2012;66(3):225-32.

3. Wake M, Clifford SA, Patton GC, Waters E, Williams J, Canterford L, Carlin JB. Morbidity patterns among the underweight, overweight and obese between 2 and 18 years: population-based cross-sectional analyses. Int J Obes. 2012. doi:10.1038/ijo.2012.86.

4. Brands B, Demmelmair H, Koletzko B. Early life programming of obesity through preinatal nutrition. Eur Gastroenterol Hepatol Rev. 2011;7(4):246-50.
5. Arenz S, Ruckerl R, Koletzko B, von Kries R. Breast-feeding and childhood obesity - a systematic review. Int J Obes \& Relat Metab Disord: J Int Assoc Stud Obes. 2004;28(10):1247-56.

6. Larnkjaer A, Hoppe C, Molgaard C, Michaelsen KF. The effects of whole milk and infant formula on growth and IGF-I in late infancy. Eur J Clin Nutr. 2009;63:956-63.

7. Koletzko B, Schiess S, Brands B, Haile G, Demmelmair H, et al. Infant feeding practice and later obesity risk. Indications for early metabolic programming. Bundesgesundheitsblatt Gesundheitsforschung Gesundheitsschutz. 2010;53(7):666-73.

8. Trabulsi J, Capeding R, Lebumfacil J, Ramanujam K, Feng P, et al. Effect of an a-lactalbumin-enriched infant formula with lower protein on growth. Eur J Clin Nutr. 2011;65:167-74.

9. Escribano J, Luque V, Ferre N, Mendez-Riera G, Koletzko B, et al. Effect of protein intake and weight gain velocity on body fat mass at 6 months of age: the EU Childhood Obesity Programme. Int J Obes. 2012;36:548-53.

10. Wells JC, Chomtho S, Fewtrell MS. Programming of body composition by early growth and nutrition. Proc Nutr Soc. 2007;66:423-34.

11. Fields DA, Demerath EW. Relationship of insulin, glucose, leptin, IL- 6 and TNF- $\alpha$ in human breast milk with infant growth and body composition. Pediatr Obes. 2012;7:304-12. doi:10.1111/j.20476310.2012.00059.x.

12. Lawrence. Does breastfeeding protect against overweight and obesity in children? A review. Child Obes. 2012;6(4):193-7.

13. McCrory C, Layte R. Breastfeeding and risk of overweight and obesity at nine-years of age. Soc Sci Med. 2012;75(2):323-30.

14. Scott JA, Ng SY, Cobiac L. The relationship between breastfeeding and weight status in a national sample of Australian children and adolescents. BMC Publ Health. 2012;12:107-12.

15. Seach KA, Dharmage SC, Lowe AJ, Dixon JB. Delayed introduction of solid feeding reduces child overweight and obesity at 10 years. Int J Obes. 2010;34:1475-9.

16. Caleyachetty A, Krishnaveni GV, Veena SV, Hill J, Karat SC, Fall CHD, Wills AK. Breastfeeding duration, age of starting solids and high BMI risk and adiposity in Indian children. Matern Child Nutr. 2011. doi:10.1111/j.1740-8709.2011.00341.x.

17. •• Li R, Magadia J, Grummer-Strawn LM. Risk of bottle-feeding for rapid weight gain during the first year of life. Arch Pediatr Adolesc Med. 2012;166(5):431-6. doi:10.1001/archpediatrics.2011.1665. This longitudinal study provides an interesting comparison of different feeding methods (bottle, breast, or combination) and, importantly, bottle content (formula versus breast milk) and the effect on weight gain in infants from birth to 1 year of age. The results show that mode of delivery is extremely important and this has implications for how the protective effects of breast milk/breastfeeding are viewed.

18. Li R, Fein SB, Grummer-Strawn LM. Do infants Fed from bottles lack self-regulation of milk intake compared with directly breastfed infants? Pediatrics. 2010;125(6):e1386-93. doi:10.1542/peds.20092549.

19. DiSantis K, Collins BN, Fisher JO, Davey A. Do infants fed directly from the breast have improved appetite regulation and slower growth during early childhood compared with infants fed from a bottle? Int J Behav Nutr Phys Act. 2011;8:89.

20. Redsell SA, Atkinson P, Nathan D, Siriwardena AN, Swift JA, et al. Parents' beliefs about appropriate infant size, growth and feeding behaviour: implications for the prevention of childhood obesity. BMC Publ Health. 2010;10:711.

21. Lakshman R, Ogilvie D, Ong KK. Mothers' experiences of bottlefeeding: a systematic review of qualitative and quantitative studies. Arch Dis Child. 2009;94:596-601. doi:10.1136/adc.2008.151910.

22. Kramer MS, Kakuma R. The optimal duration of exclusive breastfeeding: a systematic review. Geneva: World Health Organization; 2002.

23. Grote V, Schiess SA, Closa-Monasterolo R, Escribano J, Giovannini $\mathrm{M}$, et al. The introduction of solid food and growth in the first $2 \mathrm{y}$ of 
life in formula-fed children: analysis of data from a European cohort study. Am J Clin Nutr. 2011;94(6 Suppl):1785S-93S.

24. Moorcroft KE, Marshall JL, McCormick FM. Association between timing of introducing solid foods and obesity in infancy and childhood: a systematic review. Matern Child Nutr. 2011;7(1):326. doi:10.1111/j.1740-8709.2010.00284.x.

25. Wilson AC, Forsyth JS, Greene SA, Irvine L, Hau C, Howie PW. Relation of infant diet to childhood health: seven year follow up cohort of children in Dundee infant feeding survey. BMJ. 1998;316:21-5.

26. Scott JA, Binns CW, Graham KI, Oddy WH. Predictors of the early introduction of solid foods in infants: results of a cohort study. BMC Pediatr. 2009;22(9):60.

27. Huh SY, Rifas-Shiman SL, Taveras EM, Oken E, Gillman MW. Timing of solid food introduction and risk of obesity in preschoolaged children. Pediatrics. 2011;127(3):e544-51.

28. Burdette HL, Whitaker RC, Hall WC, Daniels SR. Breastfeeding, introduction of complementary foods, and adiposity at $5 \mathrm{y}$ of age. Am J Clin Nutr. 2006;83(3):550-8.

29. Reilly JJ, Armstrong J, Dorosty AR, Emmett PM, Ness A, Rodgers I, et al. Early life risk factors for obesity in childhood: cohort study. BMJ. 2005;330:1357-9.

30. Fewtrell MS, Lucas A, Morgan JB. Factors associated with weaning in full term and preterm infants. Arch Dis Child Fetal Neonatal Ed. 2003;88(4):F296-301.

31. Griffiths LJ, Smeeth L, Hawkins SS, Cole TJ, Dezateux C. Effects of infant feeding practice on weight gain from birth to 3 years. Arch Dis Child. 2009;94(8):577-82.

32. •• Rossem LV, Kiefte-de Jong JC, Looman CW, Jaddoe VW, Hofman A, et al. Weight change before and after the introduction of solids: results from a longitudinal birth cohort. Br J Nutr. 2012;5:1-6. Findings from a birth cohort indicate that before solid foods are offered, weight gain is higher in children who are then introduced to solids early (3-6 months) compared to those introduced before 3 months or after 6 months. After solids are introduced, children given solids before 6 months demonstrate a relative decrease in their BMI, suggesting that introducing solid foods before 6 months does not predict child BMI.

33. Foote KD, Marriott LD. Weaning of infants. Arch Dis Child. 2003;88(6):488-92.

34. Campbell K, Crawford D, Ball K. Family food environment and dietary behaviors likely to promote fatness in 5-6 year-old children. Int J Obes. 2006;30:1272-80.

35. Hennessy E, Hughes SO, Goldberg JP, et al. Parent behavior and child weight status among a diverse group of underserved rural families. Appetite. 2010;54:369-77.

36. Galloway AT, Fiorito LM, Francis LA, et al. 'Finish your soup': counterproductive effects of pressuring children to eat on intake and affect. Appetite. 2006;46:318-23.

37. Farrow CV, Blissett J. Controlling feeding practices: cause or consequence of early child weight? Pediatrics. 2008;121:e164-9.
38. Clark HR, Goyder E, Bissell P, et al. How do parents' childfeeding behaviours influence child weight? Implications for childhood obesity policy. J Public Health. 2007;29:132-41.

39. Huang SH, Parks EP, Kumanyika SK, et al. Child-feeding practices among Chinese-American and non-Hispanic white caregivers. Appetite. 2012;58:922-7.

40. • Gross RS, Mendelsohn AL, Fierman AH, et al. Maternal controlling feeding styles during early infancy. Clin Pediatr. 2011;50:1125-33. This study of mothers with infants aged between 2 weeks to 6 months old demonstrates that maternal controlling feeding practices (pressure to eat; restriction) are linked to mothers' concern about their child's future weight and highlights the early age at which some mothers report using controlling feeding practices. This has important implications for future obesity prevention strategies.

41. Rifas-Shiman SL, Sherry B, Scanlon K, et al. Does maternal feeding restriction lead to childhood obesity in a prospective cohort study? Arch Dis Child. 2011;96:265-9.

42. Brown AE, Lee MD. Maternal child-feeding style during the weaning period: association with infant weight and maternal eating style. Eat Behav. 2011;12:108-11.

43. Taveras EM, Gillman MW, Kleinman K, et al. Racial/ethnic differences in early-life risk factors for childhood obesity. Pediatrics. 2010;125:686-95.

44. Farrow C. The impact of responsive parental feeding practices upon subsequent child eating and growth: findings from the UK. Hyderabad: Royal Society funded Indo-UK symposia; 2011.

45. Stifter CA, Anzman-Frasca S, Birch LL, et al. Parent use of food to soothe infant/toddler distress and child weight status. An exploratory study. Appetite. 2011;57:693-9.

46. van Strien T, Frijters JE, Roosen RG, et al. Eating behavior, personality traits and body mass in women. Addict Behav. 1985;10:33343.

47. Vollrath ME, Tonstad S, Rothbart MK, et al. Infant temperament is associated with potentially obesogenic diet at 18 months. Int $\mathrm{J}$ Pediatr Obes. 2011;6:e408-14.

48. Blissett J, Haycraft E, Farrow C. Inducing preschool children's emotional eating: relations with parental feeding practices. Am J Clin Nutr. 2010;92:359-65.

49. Schwartz C, Scholtens PAMJ, Lalanne A, et al. Development of healthy eating habits early in life. Review of recent evidence and selected guidelines. Appetite. 2011;57:796-807.

50. Powell F, Farrow C, Haycraft E, et al. Appetite regulation in early childhood: the impact of parenting behaviours and child temperament. In Appetite: regulation, role in disease and control. Edited by Mitchell SR. Nova Publishers. 2011; $1-28$.

51. Palfreyman Z, Haycraft E, Meyer C. Development of the parental modelling of eating behaviours scale (PARM): links with food intake among children and their mothers. Matern Child Nutr. 2012. doi:10.1111/j.1740-8709.2012.00438.x 